\title{
"DE CANOA ATÉ O HOSPITAL": PROCESSOS DE TRANSFORMAÇÃO E MEDICALIZAÇÃO DAS PRÁTICAS DE PARTO EM QUILOMBOS DO RECÔNCAVO BAIANO ${ }^{1}$
}

\author{
NAIARA MARIA SANTANA NEVES
}

\begin{abstract}
RESUMO
Mirando uma diversidade de concepções e práticas relativas ao parto em quilombos dos municípios de Cachoeira e Santo Amaro na Bahia, e a interação entre estas, este trabalho busca compreender o processo de transformação no padrão de assistência ao parto nestas localidades. A partir de pesquisa de campo entre os anos de 2013 e 2016 focando as narrativas de oito parteiras das comunidades, realiza-se uma discussão acerca das interações entre saberes e práticas distintas - saberes médico-científicos e conhecimento dito "tradicional" - em um contexto de desaparecimento da prática do parto tradicional e popularização do parto hospitalar; trata-se de refletir também como (e se) os diferentes modelos de parto e saber exprimiriam distintas concepções de saúde, corpo, identidade e vida comunitária, sobre as quais, no caso dos quilombos, incidiriam dinâmicas sociais e processos históricos de interpenetração com o universo urbano e suas instituições, caracterizada por disputas entre corpos e territórios.
\end{abstract}

\section{PALAVRAS-CHAVE}

Parto; Parteiras; Quilombo; Medicalização; Etnocentrismo Sanitário.

\section{'BY CANOE TO THE HOSPITAL': PROCESSES OF TRANSFORMATION AND MEDICALIZATION OF LABOR PRACTICES IN QUILOMBOS OF THE RECÔNCAVO BAIANO}

\begin{abstract}
Looking at a diversity of conceptions and practices regarding quilombo childbirth in the municipalities of Cachoeira and Santo Amaro in Bahia, and the interaction between them, this work seeks to understand the process of transformation in the pattern of childbirth care in these localities. From a field research between 2013 and 2016 focusing on the narratives of eight midwives of the communities, a discussion is held about the interactions between different knowledge and practices - medical-scientific knowledge and "traditional" knowledge - in a context disappearance of the practice of traditional birth and popularization of hospital delivery; it is also a question of how (and if) the different models of childbirth and knowledge express different conceptions of health, body, identity and community life, on which, in the case of quilombos, social dynamics and historical processes of interpenetration urban universe and its institutions, characterized by disputes between bodies and territories.

\section{KEYWORDS}

Childbirth; Midwives; Quilombo; Medicalization; Ethnocentrism Sanitary.

\footnotetext{
${ }^{1}$ Este artigo é parte dos resultados da pesquisa de mestrado da autora, intitulada "Como as avós ou entre os doutores: Memórias de Parto e Identidade, Corpos e Territórios em Disputa no Quilombo do Kaonge, Recôncavo da Bahia", defendida em maio de 2017.
} 


\section{" DE CANOËÀ HÔPITAL ॥: PROCESSUS DE TRANSFORMATION ET DE MÉDICALISATION DES PRATIQUES DE TRAVAIL DANS LES TERRITOIRS MARRONS DU RECÔNCAVO BAIANO}

\section{RÉSUMÉ}

Cibler la diversité des opinions et des pratiques liées à l'accouchement dans quilombos dans les municipalités de Cachoeira et Santo Amaro à Bahia, et l'interaction entre ceux-ci, cet article cherche à comprendre le processus de transformation dans la norme de prestation des soins dans ces endroits. De la recherche sur le terrain entre les années 2013 et 2016 se concentrant sur les récits de huit communautés de sages-femmes, mène une discussion sur les interactions entre les connaissances et les pratiques différentes - connaissances médicales et scientifiques et les connaissances dites « traditionnelles »- dans un contexte la disparition de la pratique de la naissance traditionnelle et la vulgarisation de l'accouchement à l'hôpital; il est aussi comment reflète (et si) les différents modèles de prestation et de savoir exprimerait différentes conceptions de la santé, le corps, l'identité et la vie communautaire, sur lequel, dans le cas des quilombos, affectent la dynamique sociale et les processus d'interpénétration historiques avec univers urbain et ses institutions, caractérisé par des différends entre corps et territoires.

\section{MOTS-CLÉS}

Accouchement; Sages-femmes; Quilombo; Médicalisation; Ethnocentrisme Sanitaire.

\section{"DE LA CANOA AL HOSPITAL ": PROCESOS DE TRANSFORMACIÓN Y MEDICALIZACIÓN DE LAS PRÁCTICAS LABORALES EN LOS QUILOMBOS DEL RECÔNCAVO BAIANO}

\section{RESUMEN}

En el caso de los municipios de Cachoeira y Santo Amaro en Bahía, y la interacción entre éstas, este trabajo busca comprender el proceso de transformación en el patrón de asistencia al parto en estas localidades, mirando una diversidad de concepciones y prácticas relativas al parto en quilombos de los municipios de Cachoeira y Santo Amaro en Bahía. A partir de investigación de campo entre los años 2013 y 2016 enfocando las narrativas de ocho parteras de las comunidades, se realiza una discusión sobre las interacciones entre saberes y prácticas distintas - saberes médico-científicos y conocimiento dicho "tradicional" - en un contexto de desaparición de la práctica del parto tradicional y popularización del parto hospitalario; se trata de reflexionar también cómo (y si) los diferentes modelos de parto y saber expresar distintas concepciones de salud, cuerpo, identidad y vida comunitaria, sobre las cuales, en el caso de los quilombos, incidirían dinámicas sociales y procesos históricos de interpenetración con el mismo el universo urbano y sus instituciones, caracterizadas por disputas entre cuerpos y territorios.

PALABRAS CLAVE

Parto; Parteras; Quilombo; Medicalización; Etnocentrismo Sanitario. 
Juci terminou de estender as roupas e sentou um pouco com a gente, não lembro bem como, mas o assunto sobre parto surgiu. Dona Vardé nos conta sobre seus partos, antes da parteira chegar ela mesma fazia seus banhos e os tomava, a exemplo do banho de mentraste com algodão. Diz que 'a dor de menino homem macho' é mais quente ou menos espaçada, vem de uma vez; a de 'menina fêmea' é ritmada, vem, para, volta. Ela paria com parteiras, mas também pariu sozinha ou acompanhada por mulheres próximas. Parece que as mulheres sabiam mesmo parir, sabiam o que usar, como fazer, como se cuidar, e estavam de alguma maneira preparadas para acompanhar ou amparar umas às outras, para ao menos aparar o menino que descia. Dona Vardé conta de um dos seus partos, aquele que aconteceu no dia da festa de caboclo, lembra dos fogos após o parto, ela já chamava pelo caboclo antes de parir para ajudar a fazer seus partos. Neste dia, após o nascimento, Zezé, pai de Dona Ju, que também era liderança do terreiro, mandou para ela uma garrafa de cachaça e ela tomou. Ela disse: "cachaça com gengibre, minha mãe colocou ervas, eu tomei, era mãe ir pra cozinha que eu dava mais um gole". Ela recordou que gostava de tomar cachaça para isso, em seu melhor parto ela não sentiu nada pois havia tomado dois litros de cachaça numa manhã. Ao fim do seu relato, eu recordei uma fala da própria Dona Vardé, ainda no ano de 2014, ao me contar sobre as manobras para 'virar menino' realizadas pela parteira Mãe Toninha: 'se um médico sabe disso, com certeza ia dizer que tá errado.

[Diário de Campo, 13 de junho de 2016]

\section{INTRODUÇÃO}

Nesse artigo concentro-me em olhar para o corpo e рага uma diversidade de concepções e práticas relativas ao parto em quilombos dos municípios de Cachoeira e Santo Amaro na Bahia. A gestação e o parto são momentos de grande importância na vida das mulheres - e, por extensão, de todo o agregado familiar, doméstico, de residência contígua e comunitária - dotados de aspectos diversos, como eventos complexos que são, não obstante marcados por experiências únicas que envolvem o binômio mãe/mulher e filho. Essa complexidade envolve aspectos culturais, sociais, psicológicos, sexuais, familiares, espirituais, econômicos e físicos, todos estes fatores influentes na maneira como as mulheres se relacionarão e viverão estas experiências.

Em termos históricos, no Brasil, o século de XIX marca o advento da medicina obstétrica enquanto ramo do conhecimento científico, acompanhado por um processo de higienização, normatização e medicalização, que fez declinar, progressivamente a partir desse período, o padrão de partos atendidos principalmente por mulheres, as chamadas "parteiras", mobilizando saberes inscritos em sistemas específicos de conhecimento mais próximos da chamada medicina popular ou familiar (TORNQUIST, 2002, p. 8; VIEIRA, 2003, p. 23). Com a crescente urbanização do país e a consolidação da medicina e das instituições médico-hospitalares, e a partir de uma interpenetração entre diferentes espaços e dinâmicas sociais, as técnicas e acepções de cuidado com a saúde, corpo, gravidez, parto e puerpério são transformadas.

Assim, ao analisar a interação entre o corpo e o parto, somos levadas a compreender o processo de transformação no padrão de assistência ao parto em comunidades tradicionais. Рara 
essa recuperação nestas localidades a partir da perspectiva e das memórias de parteiras locais. A partir de extensa pesquisa de campo entre os anos de 2013 e 2016 focando as narrativas de oito parteiras das comunidades do Engenho da Ponte e Kaonge em Cachoeira, e Acupe, São Bráz, Derba e Pedra em Santo Amaro, realiza-se uma discussão acerca das interações entre saberes e práticas distintas - saberes médico-científicos e conhecimento dito "tradicional" - em um contexto de desaparecimento da prática do parto tradicional e popularização do parto hospitalar. Trata-se de refletir também como (e se) os diferentes modelos de parto e saber exprimiriam distintas concepções de saúde, corpo, identidade e vida comunitária, sobre as quais, no caso dos quilombos, incidiriam dinâmicas sociais e processos históricos de interpenetração com o universo urbano e suas instituições, caracterizada por disputas entre corpos e territórios.

\section{ABRINDO E APONTANDO CAMINHOS E MÉTODOS}

A pesquisa, da qual fazem parte os dados e resultados trazidos neste artigo, se desenhou metodologicamente compreendendo a antropologia como uma disciplina que busca respostas densas, considerando a complexidade de todo contexto e de cada tema e questão. A sua fonte de dados mais garantida é olhar, ouvir, estar em relação e ser participante, mais do que observador, como aponta McCallum (2001, p. 5). A relação pensada sob esta ótica implicou convivência cotidiana com os grupos e os locais estudados, apostando no potencial interacionista, compartilhando experiências, construindo co-presença, inclusive visando driblar hierarquias entre lugares de fala no texto escrito, acolhendo problematizações da antropologia mais contemporânea e parte da crítica pós-moderna. Foram realizadas oito viagens a campo em um período de três anos, as personagens que povoam a pesquisa são oito parteiras localizadas, com as quais conversei e entrevistei; seis mulheres que tiveram experiências de parto distintas hospitalar com médicos, domiciliar com parteiras ou ambos; um homem, neto de uma parteira de grande importância na região, e aspirante a parteiro; e cinco lideranças comunitárias quilombolas, principalmente da comunidade Kaonge.

O encontro do Rio Paraguaçu com o mar da Baía de Todos os Santos forma uma área estuarina com extensos manguezais e grande potencial de navegabilidade que marca a região da Bacia do Iguape, a qual se destacou até o século XIX como centro de formação e exportação de capital, tendo como base da economia o regime agro escravista, com produção e

beneficiamento da cana-de-açúcar, "transformada em açúcar - ouro branco da época" (de acordo com a descrição das próprias comunidades nos mapas biorregionais produzidos por moradores), e posteriormente de fumo. Ainda de acordo com os mapas produzidos pelas 
comunidades, а área era um grande complexo agroindustrial, repleto de engenhos de cana-deaçúcar com suas respectivas senzalas, possuindo, hoje, a maior concentração de ruínas de engenhos do estado da Bahia. No período colonial, os mangues e o estuário já eram utilizados pelos grupos de negros e negras para fins de atividade de pesca e mariscagem. A atividade produtiva atual é caracterizada pela pesca estuarina, coleta de mariscos nos mangues, cultivo familiar de ostras e agricultura em pequena escala para fins de subsistência e extração vegetal, principalmente do dendê e da piaçava utilizados na produção azeite de dendê, utensílios e artesanatos.

\section{CONSIDERAÇÕES SOBRE CORPO E PARTO}

Compreender esse objeto particular, o parto, supõe refletir sobre sua natureza social, mas também orgânica, fisiológica, e, assim, voltar o olhar para a própria noção de corporeidade e para todo um emaranhado de práticas, discursos, imaginários e representações que impregnam a noção de corpo na modernidade. O "corpo", objeto inscrito no cerne tanto da vida individual quanto coletiva, pode ser entendido tanto como veículo que identifica e dota os indivíduos de sua condição de existência, quanto instrumento pelo qual se institui um mundo de sentidos. Por isso, como afirma Le Breton (2011, p. 8 e 9), "cada sociedade, no interior de sua visão de mundo, delineia um saber singular sobre o corpo: seus elementos constitutivos, suas performances, suas correspondências etc.", de modo que, por serem "as concepções do corpo [...] tributárias das concepções da pessoa, [...] nas sociedades tradicionais o corpo não se distingue da pessoa [e, assim,] entre o homem, o mundo e os outros, um mesmo estofo reina com motivos e cores diferentes, os quais não modificam em nada a trama comum".

Embora um fenômeno fisiológico e, portanto, tomado como "natural" (e, por conseguinte, "universal"), o parto é vivenciado e significado de maneira singular em diferentes sociedades. Como afirma Maria Carranza (1994, p. 32), o parto é sempre influenciado pela "cultura", mediado por concepções de saúde, corpo, feminilidade, vida humana, entre outros. É no corpo, este mesmo que materializa a dimensão fisiológica do parto, que também estão inscritas as dimensões simbólicas e culturais que dão sentido a estas experiências. Neste mesmo sentido, Marcell Mauss (2005, p. 412) e Pierre Clastres (1995, p. 11), já falavam sobre técnicas corporais aprendidas e sobre a importância da observação de rituais relativos ao corpo, como o parto, enquanto maneira de validar a afirmação da diversidade de sistemas culturais e dinâmicas sociais. 
O suposto "corpo moderno", não obstante, seria construído de maneira muito diferente. No mesmo diapasão que Le Breton, Emily Martin (2006, p. 107) sublinha, na ideia moderna de "corpo-máquina", um "afastamento do 'Eu' do corpo", um movimento de isolamento, portanto, do sujeito em relação aos outros, ao cosmo e a si mesmo. Sobre esse corpo, tomado como sistema funcional e necessariamente "produtivo", é que incidiria a criação desse "novo imaginário do parto" (ainda segundo MARTIN, 2006, p. 245), um pequeno capítulo da constituição de saberes disciplinares - e legitimados pelo apelo a uma episteme científica que passam a tratar eventos fisiológicos (e o próprio "corpo") como apartados das trajetórias socioculturais e afetivas dos sujeitos.

Um dos desafios teóricos é pensar como tanto a "mulher", quanto o "corpo", bem como suas interações com as tecnologias reprodutivas (como apontado por STRATHERN, 1995, p. 20 dentre outros) e com as transformações contemporâneas de concepções relativas à saúde e cuidado, se tornam objetos de disputa, em torno dos quais, acerca da questão do parto, especificamente, e como aponta a literatura (DINIZ, 2005, p. 17; ROHDEN, 2001, p. 141; MONTICELI, 1997, p. 178), se estabelecem movimentos de desconstrução desse imaginário atravessado por um saber disciplinador manifesto nos discursos e práticas da medicalização. Assim, no que diz respeito às experiências e práticas que, em dadas comunidades, como no caso aqui considerado, por força do vínculo que estabelecem entre técnicas e percepções do corpo e processos de afirmação identitária, caso apelem a modelos de restituição dessa solidariedade interpessoal e de reconexão entre as noções de corpo e pessoa, tornaria nítida uma dimensão conflituosa da relação entre formas de conhecimento e práticas distintas, uma controvérsia epistêmica, de natureza também política, sobre a qual importa igualmente refletir.

Como sugere Alves (2010, p. 4), padrões de conhecimento e seus paradigmas, enquanto conjuntos "de valores, princípios, técnicas e hábitos (e mesmo crenças), compartilhados", tomados como "modelos", são a um só tempo produtores, mas também produtos de uma dinâmica social; o que, nesse sentido, implica em reconhecer as relações de poder de que emergem e de que se investem, bem como as transformações a que estão sujeitos, seja no curso da distinção entre gerações como propulsora de diferentes percepções (ainda conforme ALVES, 2010), seja pelo deslocamentos constantes das posições de poder e de seus discursos legitimadores no quadro dos movimentos gerais dados numa sociedade. Assim, a fim de pensar as controvérsias em torno ao parto e, por conseguinte, aquilo em que são afetadas por representações sociais e práticas em saúde/doença (ALVES; RABELO, 1998, p. 22), bem como por processos de correlação entre medicalização e controle social (CONRAD, 1992, p. 201), seria preciso tentar restituir a força autolegitimadora de um paradigma médico-hospitalar, 
que se impõe como modelo de assistência ao parto, às suas condições históricas e sociais de emergência, procedendo a uma espécie de "arqueologia do saber", no sentido de Foucault (1987, p. 189), bem como pensar sobre as condições de produção histórica da "subalternização" (no sentido, por exemplo, de SPIVAK, 1999, p. 54) de saberes que se apresentam como alternativos a tal paradigma, tal como aqueles que são mobilizados, no interior das comunidades do Vale do Iguape, em torno às suas práticas e discursos sobre o parto "à maneira das avós".

\section{O PARTO ENTRE AS AVÓS}

Quando falamos em "parto tradicional" caímos em uma questão, já tratada anteriormente, referente à superar a ideia de tradicionalidade como uma prática imutável na história. Tradição é vista aqui como um conceito, uma abstração, capaz de reunir processos históricos, conhecimentos e práticas singulares, distintas do processo ocidental, industrial, capitalista, desenvolvimentista e científico no sentido tout court. Segundo Sahlins (1997, p. 110), a cultura enquanto processo prevê um movimento contínuo de consciência e atualização da tradição, ainda que preserve traços fundamentais de seu conteúdo ou da forma como os sentidos são organizados. Este tipo de parto é caracterizado, a partir das narrativas por ser um evento social, familiar e íntimo ao mesmo tempo, pensado, de forma empírica e acionando uma lógica perceptual e de qualidades sensíveis pelas parteiras, tendo como destaque o evidente respeito à fisiologia do corpo da mulher e a aproximação com o ambiente biofísico - uso das plantas, ervas, chás, banhos, caminhadas, trabalho na maré e mangue durante o trabalho de parto, sendo esta última característica também de um parto visto como um evento natural (no sentindo de habitual e acessível), não obstante sua importância e singularidade.

O parto é para as comunidades quilombolas do Vale do Iguape, um momento que faz parte da vida da mulher, do casal, da família e do grupo; diferente do parto em contextos urbanos medicalizados, visto como um evento da medicina, associado a riscos constantes e patologizado. Importante destacar que este tipo parto é também um evento que afirma os conhecimentos e poder das mulheres, um evento compartilhado basicamente pelas mulheres de uma mesma família e/ou grupo, incluindo a parteira, figura que detém os conhecimentos e técnicas para lidar e significar aquele processo.

No caso específico dessas comunidades, o parto dito "tradicional", realizado com "parteiras", como modelo preponderante de assistência ao parto, era, segundo a narrativa das próprias comunidades, uma prática ainda recorrente há cerca de trinta anos, embora venha sofrendo alterações há pelo menos oitenta anos. Este parto, nas referidas comunidades, ocorre atualmente apenas "quando necessário", sobretudo em casos em que, por variadas razões, não é 
possível aceder à assistência médico-hospitalar. Desta forma, "quando necessário" é um termo bastante usado por todas as parteiras entrevistadas, que dizem fazer parto "se for necessário" ou "quando necessário".

Ao chegar às comunidades estudadas e perguntar por parteiras, a princípio, é comum ouvir como resposta "todas já morreram" ou "isso não existe mais". Aos poucos, com cada vez mais proximidade e conversa, é possível ir chegando aos nomes e endereços das parteiras vivas e também das que já se foram. É curioso pensar que, embora exista um número considerável de parteiras vivas e dispostas a fazer parto, em geral, elas são tratadas pelas próprias comunidades como inexistentes no presente, como figuras que, embora de extrema importância e a quem se reporta grande respeito, estão vivas apenas nas memórias, nos compartilhamentos de "causos" e nas histórias das comunidades e, mais recentemente, como mais uma maneira de comunidades como o Kaonge afirmarem uma identidade quilombola ancestral. A categoria "parteira quando/se necessário" emerge após o processo de transformação e medicalização das práticas de parto na região, é a maneira pela qual as parteiras existem e atuam hoje, de maneira um tanto clandestina e um tanto decepcionada.

A gestação e o parto eram momentos que possibilitavam experiências de compartilhamento entre as mulheres de várias gerações e constituíam laços de compadrios e parentesco. As mulheres tinham certa autonomia sobre seus corpos e seus processos de reprodução e parturição, o que não significa que elas possuíam mais autonomia de maneira absoluta naqueles contextos, uma vez que os relatos de violências diversas contra as mulheres são recorrentes, mas que existia um determinado controle praticado por elas a nível individual e coletivo (entre mulheres de um mesmo grupo e/ou família) no que concerne ao parto, aos abortos e às vezes à contracepção. Dona Jenete, por exemplo, parteira de Acupe relatou que "era chamada para resolver aborto, fazer curetagem".

Dona Maria, moradora antiga do Dendê, contou:

"Eu não sabia se estava grávida ou parindo, não sentia nada, sentia o começo das dores, ia pra maré trabalhar, mariscar, a parteira mandava a gente tocar o dia até as hora chegar. Eu ia pra maré e ficava lá cuidada por Nanã, nas proteção dela até a dor esquentar mesmo e voltar pra casa e mandar chamar a parteira." [Diário de Campo, 29 de setembro de 2013]

A ideia de um conhecimento tradicional que é empírico e baseado em unidades perceptuais é abordada Lévi-Strauss em seu livro "O pensamento selvagem" (1962, p. 68) e reafirmada por Carneiro da Cunha (2009, p. 8). Embora, perceptual, este tipo de conhecimento não pode ser confundido e classificado como um saber fundado em falta de critério ou de uma lógica, ou como simplesmente superstição. Ehrenreich \& English (1981, p. 10) afirmam que as chamadas bruxas e as parteiras, também acusadas de bruxaria na Idade Média eram mal vistas 
pela Igreja Católica justamente por serem "empíricas, de atitude indagadora e confiantes de sua própria capacidade, sendo sua magia a ciência de sua época e contexto".

Ehrenreich \& English (1981, p. 13) vão ainda mais longe ao afirmar que muitos dos remédios largamente utilizados hoje para determinadas afecções e substâncias utilizadas no parto ou para evitar partos antes da hora como a beladona foram, originalmente, descobertas por estas mulheres, cientistas populares que desenvolviam seus conhecimentos a partir das demandas que surgiam, das experiências práticas a partir destas demandas e do compartilhamento oral de suas descobertas, exatamente como as parteiras ditas tradicionais.

Dona Raimunda, parteira de Acupe, relatou em um dos nossos encontros como começou a partejar e como lidou com situações inesperadas e com partos considerados pela medicina atual, tanto a mais ortodoxa quanto a chamada Medicina Baseada em Evidências e até a maior parte das defensoras da humanização do parto, como impossíveis de acontecerem de forma natural, situações em que é rotina recorrer a uma cirurgia cesariana, a exemplo de um parto de placenta prévia:

"Não tenho formatura, tenho coragem, vontade e força que Deus me deu para salvar uma pessoa que tiver coragem. Meu primeiro parto aconteceu por necessidade, minha mãe era parteira, arranjava assim como eu tô te dizendo, ela estava na lavoura e foram lá em casa chamar, eu via o que era que ela fazia comigo e fui. Peguei um cordãozinho, lavei, enxuguei com um paninho alvo e encharquei de álcool e marrei, cortei o cordãozinho dela. Uma coisa e outra, uma coisa e outra, chamei por Deus, deus ajudou e a criança nasceu. A criança nasceu e eu ajeitei a barriga dela, escorri a barriga dela. Com três dias eu dei um purgante para limpar a barriga, um purgantezinho, você não conhece, a palma da rainha e lona branca, cebola branca, meu de abelha, mel de uruçu, óleo de rícino, bota pra ferver e quando acaba despejei num copo, bati bem e dei a ela. Aquilo ali desarranja, depois um frasco de água inglesa. (...) Um dia aconteceu uma coisa que eu não sei nem dizer, nunca tinha visto um negócio daquele, tava fazendo o parto e quando vi a placenta tava saindo primeiro que o menino. Eu fui recolhendo a placenta, chamando ela pra dentro pra dar passagem ao bebê. Recolhi a placenta, a mulher era corajosa e eu fui falando pra ela com carinho 'vamo, minha fia'. Coloquei óleo de amêndoa na mão e calcei a luva, fui caçando e caçando com a mão e empurrando e chamando com a outra mão, ai pronto, deu passagem ao bebê, quando cabo de nascer o bebê e antes de cabá de passar a cabeça ela caiu no pescoço do menino. Eu nunca vi placenta nascer primeiro da criança". [Diário de Campo, 21 de julho de 2015]

Outra característica muito abordada em diversos trabalhos sobre parteiras ditas tradicionais, e aqui é possível citar Fleischer (2011, p.258), é uma percepção diferenciada do tempo, atenta às singularidades de cada corpo, cada mulher e cada parto. Esta percepção estendida do tempo está também associada à paciência para realização do parto normal.

\footnotetext{
${ }^{2}$ A entidade "placenta prévia" consiste na implantação placentária no segmento inferior (SI), distando no máximo $7 \mathrm{~cm}$ do orifício interno (OI) do colo do útero, compondo juntamente com o descolamento prematuro e a rotura uterina, causas de sangramento vaginal do terceiro trimestre de gestação. Ela é classificada de acordo com a proximidade com o colo em placenta prévia: centro-total (recobre o orifício interno do colo do útero), centro-parcial (recobre parcialmente o orifício interno), marginal (margeia o orifício interno do colo do útero) e lateral (distando até $7 \mathrm{~cm}$ do orifício interno do colo) de acordo com Torloni, Moron \& Camano (2001).
} 
Diferente dos partos nos contextos hospitalares das sociedades urbanas industrializadas, nas quais os médicos são formados e estão inseridos em uma lógica produtivista de saúde e parto. Neste tipo de sociedade é possível identificar a mercantilização da saúde e do parto, percebê-lo dentro de uma linha de montagem na qual o bebê é o produto final e pouco importa a experiência e o processo.

A antropóloga Martin (2006) fala, em seu livro "A mulher no corpo", por exemplo, a partir da ideia moderna do corpo como uma fábrica, do corpo repartido e alienado, da separação do "eu" do corpo, característica das sociedades industrializadas contemporâneas. A própria lógica do Estado ao lidar com a saúde enquanto números e estatísticas, com "produtividade de partos", deixando de lado outras dimensões tão caras a este momento da vida reprodutiva de boa parte das mulheres e homens. Isso é evidente na fala de Manoel Rodrigues, coordenador do Fórum da Rede Cegonha da Região Metropolitana de Salvador. Em entrevista realizada no dia 21 de novembro de 2015, Manoel, apesar de afirmar o "esgotamento do modelo obstétrico do Brasil e sua crise atual", de fazer diversas críticas à "perversidade da gestão em saúde e do direcionamento dos recursos", chama atenção para o objetivo das gestões em atingir "qualidade mais produtividade", "o serviço de saúde tem que ter produtos, metas e mensurar".

Na visão dos moradores e moradoras do Kaonge há uma relação direta entre os sentidos da vida em comunidade, a religião e a prática e os conhecimentos das velhas parteiras. A fala de Joca, em conversa informal no dia 15 de junho de 2016, quando associada à fala de Ananias, também em conversa informal no mesmo dia, e à fala de Juci, no dia 14 de junho de 2013, revela a importância da figura das parteiras e de suas memórias como uma força material e simbólica aglutinadora e constituidora da identidade local. Joca afirma a existência de um "bem viver" na comunidade que é vista como "um lugar de amor e perdão, onde existem coisas que a gente não vê, mas são muito importantes, o que um não vê o outro vê, o que orixás dizem". Já Ananias diz que "as parteiras não fazem partos sozinhas, uma parteira não é uma parteira, elas são lideranças religiosas". Juci chamava atenção para a importância de mapear as parteiras da região e seus conhecimentos, principalmente a ligação deste e da prática de parto com a religiosidade e os saberes relativos às plantas e ao território. Ora, o que enxergo aqui é justamente uma afirmação deste tipo de conhecimento que Lévi-Strauss (1962) chama de conhecimento baseado na percepção, a afirmação da relevância da figura da parteira e dos saberes que ela mobiliza para constituição da socialidade local, a parteira como tecelã de partos, reciprocidades, relações e sentidos que vão além da gestação e do parto.

Estas mulheres cuidavam, geralmente, da saúde comunitária, não apenas atendia a partos. Dona Janete do Acupe conta, em conversa no dia 22 de julho de 2015, que fazia 
curativos e atendia a uma diversidade de emergências em sua própria casa, inclusive emergências veterinárias. Nico, neto da parteira Mãe Toninha, hoje é encarregado de cuidar do umbigo de todas as crianças que nascem em sua comunidade. Tal qual fazia sua avó parteira, ele é responsável por estes bebês nos seus primeiros sete dias de vida. Apesar de não fazer parto e de ser homem, ele exerce um papel social similar em sua comunidade, o Dendê, e conta em conversa no dia 01 de dezembro de 2013, que gostaria de ser parteiro. Ele é também uma espécie de cuidador da saúde comunitária, se considera inclusive um profissional, faz curativos e outros atendimentos baseados nos saberes e práticas que aprendeu acompanhando e observando sua avó.

Trata-se antes de uma técnica da práxis, herdada pelo próprio contato entre corpos afetados pela experiência de compartilhar e pela experiência de mulheres com o próprio sentido do parto. Por outro lado, a dificuldade em partilhar informações para fora do grupo, ou de "assumir-se" parteira, constitui-se enquanto uma estratégia de resistência à deslegitimação das práticas e conhecimentos das parteiras tradicionais da região pelos médicos e demais atores e atrizes do sistema institucional de saúde, está associado a um processo histórico de controle e perseguição da parteira tradicional no bojo das políticas de saneamento e medicalização na região. É comum em todas as narrativas a afirmação da existência de um discurso e uma postura de desconstrução do papel e do lugar social das parteiras, de julgamento destas mulheres e muitas vezes de criminalização podendo chegar ao limite do que isso representa - parteiras que sofreram ou quase sofreram processos de médicos e/ou moradores das próprias comunidades, parteira agredida por marido simplesmente porque exercia o ofício de partejar, parteiras desistindo de partejar para preservar suas vidas. Esse discurso deslegitimador das parteiras e do próprio grupo está localizado em outro espaço caracterizado mais rudemente de urbanizado em contraposição ao rural quilombola, correspondendo também ao espaço da institucionalidade (seja médica, científica ou do Estado). O que se ouvia e ainda se ouve em certa medida nos hospitais e demais instituições são as ameaças, os perigos, as chacotas, o questionamento das práticas de cuidado exercidas por estas mulheres ainda que o próprio serviço institucional público ou privado de saúde não dê conta de garantir acesso e diálogo efetivo com as comunidades rurais quilombolas ou não.

Dona Maria chega a dizer que em casos de complicações e problemas decorrentes do parto as parteiras vão para a delegacia e os médicos não. Destaca também a banalização e naturalização da violência contra a mulher "naquele tempo", citando um caso ocorrido no Kalembá, comunidade quilombola vizinha ao Dendê e ao Kaonge.

"Se eu fosse parteira não queria mais fazer parto, porque tem médicos, naquela época não existia médico, mas agora tem médico, vai para o médico porque se por acaso a parteira fizer 
um parto e surgir qualquer coisa errada ela vai para delegacia e o médico não vai não. [...] Quase, quase acontece, só não aconteceu porque quem fez não deixou ir para a delegacia. Um tal aqui, não foi aqui na nossa residência aqui no Dendê não, foi ali no Kalembá. A mulher estava grávida, ele deu umas pancada na mulher, aquele tipo de homem de antes, aqueles homens que gostavam de bater muito nas mulheres. Aí quando ela deu a dor para ganhar neném, o neném nasceu, justamente com a parteira, com a pobre coitada, aí nasceu, quando o menino nasceu ela viu logo assim a criança já doente, ela disse: ó esse menino tá doente. $E$ aqui tinha um cara que se transformava, que dizia que era médico, todo mundo socorria, dizia: - Ah, Dr. Erasmo, Dr. Erasmo. Mas a parteira da gente própria e mesmo daqui, justamente a minha, a minha com quem tive meus filhos, quando acaba de cortar o "imbigo" da criança ela botava sal no "imbigo" da criança. Agora amanhã ela ainda continuava, mas depois ela fazia o que? Pegava fumo de corda, torrava, fazia aquele pózinho bem fininho, aí quando dava banho na criança enxugava bem enxugadinho com merthiolate, enxugava bem enxugadinho $e$ quando acabar colocava aquele pouquinho de pó em cima. A gente levava quase um mês fazendo isso, mesmo que o "imbigo" caísse, mas curava com aquele pó. Aí ela como essa criatura fez o parto do menino e aí cortou o "imbigo" aí botou o sal, logo o menino morreu. O menino morreu, antes de menino morrer foi para Erasmo, Erasmo chegou lá e disse que foi porque botou sal. Aí quando menino morreu, a mãe mais a tia queria botar pra delegacia, mas o tipo do pai que sabia o que ele fez não deixou. Se deixa a pobre da bichinha ia se achar na delegacia. Então esse caso eu tenho pra falar. Aconteceu aqui no meio da gente." [Diário de Campo, 29 de setembro de 2013]

Ao trazer estas reflexões que emergiram a partir das falas dos moradores do Vale do Iguape e das experiências compartilhadas em campo, o que pretendo afirmar é que me parece haver uma correlação entre as disputas políticas e territoriais vivenciadas pelas comunidades e moradores daquela região e as disputas entre epistemes e corpos - acepções e práticas de cuidado com a saúde, a gestação e o parto. É comum ouvir das parteiras, e aqui posso citar Dona Maria Teresa e Dona Binha, que médicos e enfermeiras muitas vezes batiam ás suas portas convidando-as para participar de cursos de formação e integrar equipes hospitalares, era certo que se a parteira se recusasse logo mais estes profissionais voltavam, as vezes acompanhados de delegados ou policiais, acusando-as do exercício ilegal da obstetrícia. De caso em caso a lógica do medo foi se disseminando e contribuindo para que estas mulheres largassem seus postos de parteiras. O argumento desenvolvido aqui diz respeito também a um paralelo entre o processo de medicalização, o processo de criminalização e perseguição da parteira e curandeira tradicional, e os processos de disputas territoriais e identitárias. Medicalizar e hospitalizar o parto significou também descosturar uma teia de relações, saberes e práticas, transformar os sentidos da vida comunitária nos quilombos, das relações de compadrio e parentescos constituídos a partir da parteira, o lugar da parteira e da parteira tradicional. Os corpos das mulheres quilombolas seriam, tanto quanto seus territórios, disputados, em termos políticos, práticos e simbólicos, e não muito raramente, a partir da gramática da violência tomando o espaço da gramática do cuidado (seja da terra, do território, da vida comunitária, ou dos corpos e vidas). 
É importante lembrar que este artigo aborda uma prática de parturição quase extinta, se a tomarmos tais quais descritas nas memórias das parteiras interlocutoras da pesquisa, uma prática que, ainda que aconteça eventualmente em casos bem específicos, passou por diversas transformações desde o século passado devido, principalmente, a modificações do padrão de assistência a gestação e ao parto no país, à tentativa de políticas mais centralizadas de saúde promovidas pelo Estado, ainda que não sejam facilmente acessadas pelas comunidades em questão (o que consiste também em um dos problemas atuais destas comunidades), e à transformações em decorrência da relação cada vez mais próxima com as sociedades envolventes, o Estado e todo o circuito institucional de assistência à saúde. A experiência de rememorar é encarada aqui como um recurso metodológico, político e de vivência particular e até especial. Isto porque, tanto a memória é considerada uma categoria substancial da identidade do tipo específico de comunidade em questão, quanto devido à potência do ato de rememorar enquanto experiência reflexiva, de autolocalização e inscrição, de autovalorização, de atualização e reinvenção, como fonte criadora de inovação, tudo isto no presente. Ainda que, por motivos teórico e metodológico muito óbvios, a saber, a necessidade de definir e delimitar categorias e conceitos acerca das comunidades quilombolas para que seja possível pensar antropologicamente e fazer etnografia com e sobre estes grupos, é imprescindível também considerar o que aponta Leite (1991), Arruti (2006; 2008), entre outros autores e autoras, bem como a realidade e o discurso de uma diversidade de grupos quilombolas no Brasil, que não é cabível uma generalização estanque sobre uma categoria ainda em disputa e que vem sendo politicamente construída, principalmente no fazer cotidiano dos referidos grupos e indivíduos. É certo que, como afirma Leite (1991), uma possível definição orbita em torno da consideração das especificidades de cada grupo e de sua autodefinição, da relação com terra, território, segregação racial e socioeconômica, reciprocidades, parentesco, memória e capacidade de autoorganização e estabelecimento de solidariedades (ainda que haja conflitos e instabilidades, considerando que a identidade e a etnicidade, tal qual a tradição e a cultura, para lembrar Barth (1976, p. 49), não são estáticas) para lidar com as disputas associadas a inserção destes grupos e indivíduos em um sistema macro de organização social assentado no racismo, no machismo e nas desigualdades de classe.

É importante ressaltar que, como disse Leite (1991, p. 32), há uma miríade de questões relacionadas aos quilombos contemporâneos no Brasil e reduzir suas demandas apenas à questão agrária é reduzir também sua potência, seus significados, suas vozes, suas histórias, seus modos de vida e suas construções políticas. Olhar para outras questões, tais quais saúde, parto, parteiras, curandeiras e rezadeiras, é olhar para dimensões não menos importantes que a 
disputa territorial, é olhar para suas subjetividades sem perder a oportunidade e articulá-las a questões maiores, a exemplo da própria questão agrária e das desigualdades econômicas e sociais, o machismo e o racismo institucionais a que estes grupos estão submetidos. É o começo de novas possibilidades de diálogo, compreensão e construção de políticas públicas mais efetivas voltadas para as populações quilombolas, políticas baseadas em autodeterminação e consideração das especificidades, dos saberes, das práticas e dos modos de vidas locais diversos.

A memória, esta "ilha de edição segundo as palavras do poeta jequieense Wally Salomão, se configurou, portanto, enquanto uma possibilidade das mulheres e mulheres parteiras aprofundarem suas reflexões acerca de seus conhecimentos e seu lugar social, das transformações da prática de parturição e da organização social em torno disso. Em suas falas elas trazem descrições e análises sobre a perda da reciprocidade e dos laços de parentescos contraídos a partir da parturição dita tradicional; a criminalização, perseguição, desvalorização e subjugação das parteiras frente ao Estado, a saúde institucionalizada e aos profissionais de saúde, a exemplo dos médicos e obstetras; as vulnerabilidades relacionadas a violências de gênero, de raça e obstétrica associadas; a exposição à morbimortalidade materna e infantil em face do novo modelo de assistência ao parto; o hiato entre gerações de parteiras que não conseguiram formar de fato suas sucessoras; e o desaparecimento gradual das figuras das parteiras e de um saber e prática específicos. Quando perguntada porque não faz mais parto, ainda que se diga disposta a isso "caso necessário" e que tenha feito partos "por necessidade" recentemente, Dona Raimunda prontamente responde deixando nítidas as questões apontadas acima e deixando claro que não cobrava pagamento em dinheiro pelos partos que realizava. Dona Raimunda afirmou:

"Eu tenho medo, tem médico aqui, tem ambulância. Eu já fiz mais de quatrocentos partos, um dia uma vizinha queria me acusar de ter matado um menino. Vieram me chamar aqui em casa pra fazer esse parto, a mulher tinha feito cirurgia [cesárea] há um ano. Me deu aquele negócio assim por dentro avisando, mas eu fui, quando cheguei lá o menino tava nascendo e nasceu todo despelando já, com o cordão [umbilical] solto. O menino tava era morto dentro da barriga há dias já. Foi difícil sair a placenta nesse parto, o cordão já tinha largado. Com pouco a vizinha quis dizer pra mãe que eu tinha matado o menino de parto, aí veio alguém de lá e falou 'não, o menino já nasceu despelando já'. E eu que já tenho tanto fí de umbigo, se tiver uma festa ali você vai ver, bença a minha mãe, bom dia cumadi, e por aí vai. Mas agora o pessoal também tem muita vaidade, por isso que não quer parir aqui, e no hospital tem morrido mais do que aqui, viu. Eu mesma outro fui visitar uma conhecida aqui no hospital e cheguei lá tinha uma se contorcendo de dor, largada lá, me pediu pra fazer alguma coisa por ela eu perguntei o que eu podia fazer se ela tava no hospital no meio dos médicos. Ela pediu pelo amor de deus e eu fui acudir ela, coitadinha, aparei o menino dela no hospital mesmo. Mas o pessoal hoje também ta muito mal agradecido, tem coisas que nenhum dinheiro paga, se uma pessoa fizer qualquer coisa pequena por mim nenhum milhão paga isso." [Diário de Campo, Julho de 2015] 
Sobre esta questão do pagamento pelos partos é interessante ressaltar que quase todas as parteiras trabalhavam sem recursos e retornos financeiros, as obrigavam a acumular tarefas e trabalhos. Рara as parteiras mais velhas e ligadas à prática mais próxima do que entendemos como tradicional ou lida pelo Kaonge, por exemplo, como ancestral, cobrar dinheiro por um parto não é visto com bons olhos já que o que paga o parto é a relação de parentesco contraída e os desdobramentos disso na vida cotidiana. Em Acupe encontrei um maior número de parteiras profissionalizadas, que fizeram cursos de formação e atualização voltados para parteiras curiosas, como citados anteriormente, e uma única parteira entre todas as entrevistadas, que cobrava pelos partos que realizava, coincidentemente ela era a que mais falava em uma linguagem próxima a linguagem médica e salientava a importância deste tipo de conhecimento em detrimento das práticas populares. Dona Heloína que partejava seguindo a risca toda a orientação que recebia em cursos de formação para parteiras promovidos por órgãos do Estado, se via como uma enfermeira e acusava as parteiras das comunidades de charlatãs ou curandeiras perigosas devido às suas técnicas distintas das baseadas na biomedicina, era contra o uso de chás, banhos e plantas. Há uma disputa clara entre Dona Heloína e todas as outras parteiras do Acupe com quem conversei, bem como uma diferença entre ela e as parteiras do Iguape. Todas as parteiras de Acupe falaram dela como outra categoria de parteira, e isso está relacionado com o fato de seus conhecimentos terem origens diferentes, com o fato de Dona Heloína recorrentemente criminalizar as demais parteiras e também por cobrar pelos partos que fazia. Ela se proclamava enquanto uma pessoa que disseminava práticas de higiene, que buscava trazer recursos para a comunidade, a exemplo da primeira ambulância e da atenção autoridades médicas e sanitárias. Sem dúvida ela tem relevância na história local e é também uma mais uma mulher forte ao seu modo, embora seja vista pelo grupo e pelas demais parteiras com desconfiança por parecer sempre estar mais ao lado dos de fora do que dos de dentro.

Práticas de saneamento e higiene de fato melhoram a qualidade da assistência, todas as parteiras falam sobre a importância de estar atenta a isso e da troca de conhecimentos com quem vem de fora, o que elas em geral criticam é a relação de hierarquização e criminalização. A política de formação de "curiosas" desenvolvida pelo SESP a partir da década de 1950 parecia bem clara em seus objetivos de substituir progressivamente as parteiras e os domicílios por médicos, postos de saúde e hospitais. As velhas parteiras queriam aprender, mas não ser subjugadas ou substituídas.

Ainda que as práticas de higiene e saneamento fossem importantes, a questão aqui é como e com quais fins elas foram pensadas e desenvolvidas, principalmente nas zonas rurais, nas 
"terras de preto". Medicalizar esses partos quase completamente, na prática, não possibilitaram mais qualidade absoluta na atenção ao parto e/ou o fim das mortes maternas e fetais, muitas parteiras contam que nunca perderam um menino ou mãe em um parto. Medicalizar, higienizar e sanear significou na verdade um maior controle social sobre determinados grupos e em boa medida uma descostura institucionalizada das teias sociais e culturais específicas já estabelecidas em cada localidade, do controle dos corpos e da vida das mulheres, principalmente das mulheres negras, da violência de gênero e de raça. Nem a promessa de um novo modelo de assistência à gestação e ao parto foi efetivamente cumprida, uma vez que até hoje a estas mulheres e comunidades é negado o acesso de fato à uma saúde institucionalizada e com bases biomédicas de qualidade.

\section{DE CANOA ATÉ O HOSPITAL}

De canoa até o hospital, movimento que muitas mulheres faziam e ainda fazem naquelas comunidades, o que muitas vezes acaba em partos no meio do estuário dentro das canoas, ou embaixo de bambuzais nas estradas, como me foi relatado por Iraildes moradora da comunidade do Kalembá, vizinha ao Kaonge, por exemplo, diz respeito também a um movimento maior de transformação dos padrões de assistência à gestação e ao parto nestas comunidades, de substituição dos partos domiciliares com parteiras por partos hospitalares com equipe médica, quando as mulheres conseguem de fato acessá-los, geralmente depois de muito peregrinar em busca de atendimento. Estas mulheres contam que saem de uma cidade a outra buscando local onde seja possível parir, muitas chegando à capital do estado, Salvador, após tentar vagas em maternidades pela região do recôncavo e região metropolitana de Salvador.

Inspiro-me em Lima e Hocchman (1996, p. 12) para afirmar que no bojo de uma política muito maior, voltada para o desenvolvimento de um projeto de nação e de uma pretensa classe trabalhadora "saudável" e controlada pelo Estado, estava inscrito o movimento pelo saneamento do país, principalmente das áreas rurais. A figura do Jeca Tatu trazida na literatura de Monteiro Lobato na década de 1910 precisava ser curada e superada para dar lugar a um tipo novo de cidadão brasileiro mais compatível com os desejos das classes dominantes para o país. É neste contexto de urbanização e industrialização que a doença passa a ser vista com uma importância sociológica e movimentos de saneamento e de valorização da classe médica e da medicina explodem e se desenvolvem de maneira que marca a organização da saúde no país até os dias atuais.

No âmbito destas transformações ocorreu também o início de higienização das "parteiras curiosas", de acordo com Silva e Ferreira (2011, p. 18), o boletim do Serviço Especial 
de Saúde Pública (SESP) de junho de 1948 elegia como um dos principais objetivos da instituição a promoção da saúde materna e infantil.

As autoras citadas acima e os boletins do SESP indicam a resistência das parteiras a estas transformações, tanto quanto as falas das parteiras entrevistas no processo desta pesquisa. As causas são similares, resistiam à submissão as equipes médicas, ao controle de suas práticas e conhecimentos por parte do Estado que se relacionava com as velhas parteiras curandeiras como figuras incapazes, danosas e que precisavam ser extirpadas do âmbito dos cuidados com a saúde em suas localidades para atingir o objetivo das referidas políticas higienizar, sanitarizar, medicalizar e hospitalizar o país, bem como, descosturar teias de organizações singulares locais e camponesas singulares homogeneizando a identidade nacional. As práticas e as próprias parteiras não eram vistas apenas como curiosas, mas como primitivas, o que revela o caráter destas políticas e a maneira violenta como enxergam estas mulheres e seus grupos. Uma das práticas mais criminalizadas era o tratamento do coto umbilical com cinzas, o que corrobora com as descrições das parteiras entrevistadas, de Donas Juvani e de Nico. Todos eles relataram o uso de cinzas de fumo torrado como prática terapêutica relacionada à cicatrização dos cotos umbilicais, na região do Iguape muitas parteiras foram perseguidas devido ao uso de cinzas e um grande número de mortes neonatais em decorrência de uma doença que os nativos chamam de "mal de sete dias" 3 foi associado à esta prática das parteiras, o que é comumente usado pela população local para justificar o fim dos partos ditos tradicionais na região. Embora as práticas de higiene nos partos pudessem ser alteradas para melhor desfecho destes, criminalizar as parteiras não seria a única estratégia de transformação da qualidade dos atendimentos, seria possível outras abordagens tanto para esta questão das mortes de bebês

${ }^{3} \mathrm{O}$ "mal de sete dias" é como é conhecida nas comunidades negras rurais do Recôncavo baiano uma afecção que acomete recém-nascidos, podendo resultar na morte dos bebês, denominada tétano neonatal. De acordo com o site do Ministério da Saúde do Governo Federal do Brasil, "o Tétano Neonatal (TNN) é uma doença que pode acometer recém-nascidos de dois a 28 dias de vida, independente do sexo, filhos de mães não imunizadas, cuja porta de entrada da contaminação pode ser durante o parto (por ocasião da seç̧ão do cordão umbilical com instrumentos inadequados e contaminados) ou após o parto (pelo uso de substâncias contaminadas no coto umbilical). As condições de anaerobiose (necrose do coto, corpo estranho, infecção secundária) faz com que o bacilo do C. tetani produza as toxinas e cause a sintomatologia da doença". Possui um período de incubação de aproxidamente sete dias, motivo pelo qual é chamado nas comunidades de "mal de sete dias". Segundo a vigilância epidemiológica do estado da Bahia, é caso confirmado de TNN "todo recém-nascido que nasceu e sugou bem e que após as primeiras 48 horas de vida e até o $28^{\circ}$ dia após o nascimento apresentou dificuldade para mamar ou sugar e apresentou dois ou mais dos seguintes sinais/sintomas: trismo, contratura permanente dos músculos da mímica facial, contratura labial, olhos cerrados, pele da região frontal pregueada, hiperflexão dos membros superiores junto ao tórax (posição de boxeador), hiperextensão dos membros inferiores, crises de contraturas musculares, aos estímulos luminosos, ao toque ou ao manuseio, com sinais inflamatórios ou não do coto umbilical. A principal forma de prevenir o tétano neonatal é a vacinação de todas as mulheres em idade fértil, gestantes e não gestantes, com esquema completo da vacina dT (vacina dupla bacteriana contra difteria e tétano). 
quanto para um processo de formação das parteiras que fosse menos violento com estas figuras e com os costumes locais. Mas o que estava em jogo, afinal, era o objetivo central de homogeneizar a identidade nacional, afirmar o poder central do Estado e da classe médica, a urbanização e industrialização do país, bem como a substituição do paradigma de cuidados com a saúde, dos costumes locais camponeses e a transferência do poder local das mulheres negras para os médicos homens brancos.

O etnocentrismo sanitário estava instalado no país, ou as parteiras se rendiam à nova ordem ou paravam de atuar em suas localidades, o que causou diversos impactos na socialidade local do Iguape e do Acupe, por exemplo. Os textos do SESP eram taxativos e falavam em "catequização", novas armadilhas colonizadoras para novos tempos de expropriação, apropriação e exploração das populações que se constituem até hoje enquanto minorias políticas vitimizadas pela profunda desigual social e econômica do país. Em 1953 o SESP chegou a criar uma divisão de pesquisas sociais contratando inclusive um antropólogo para compor a equipe de pesquisadores.

As parteiras do Iguape e de Acupe contam que muitas vezes foram surpreendidas em suas portas por médicos, enfermeiras, oficiais do Estado e até delegados de polícia com a finalidade de convencerem-nas a integrar cursos de formação de "curiosas", equipes de hospitais na região ou de aterrorizá-las por exercerem seus ofícios nas comunidades. Algumas delas como Dona Adna, Dona Heloína e Dona Janete atenderam a estes chamados, muitas vezes trabalhando nos hospitais ensinando os médicos que, segundo Dona Adna, mal sabiam fazer partos e terceirizavam seu trabalho para as parteiras, embora recebessem pelos partos enquanto elas muitas vezes não recebiam. Algumas assimilaram rapidamente a nova lógica, outras sequer aceitaram participar dos cursos e acabaram por ser progressivamente substituídas pelo novo modelo obstétrico.

Contudo, ao contrário do que alguns pesquisadores apontam, em um gesto romântico, maniqueísta e conservador, as práticas de parturição nas comunidades são constituídas também de vários elementos externos. As parteiras também são capazes de se apropriar, ressignificar e reproduzir práticas do modelo tecnocrático quando estas se mostram eficazes e pouco invasivas. Algo comparável ao que Lévi-Strauss chama de bricolagem. Nico, neto de Mãe Toninha, por exemplo, descreveu a importância, para o exercício do seu papel dentro da comunidade, do aprendizado de novas técnicas de cuidado a partir da observação das técnicas no ambiente hospitalar. Segundo suas próprias palavras:

"Se precisa limpar as mãos para fazer um curativo, dar uma injeção, fazer os processos no hospital, precisa também para cuidar do 'imbigo' dos meninos que nascem aqui." [Diário de Campo, dia 01 de dezembro de 2013] 
Estes dois extremos de resistência e assimilação coexistindo aponta para a construção das identidades e do próprio território pretensa e idealmente equilibrada, mas objetivamente avassaladora, revela uma postura política nas ações diárias que tende a uma busca por uma síntese mais equilibrada entre práticas, modelos de assistência, cosmologias e territorialidades.

O que apontam os discursos das mulheres do Iguape converge consideravelmente com a proposta dos/as profissionais e militantes da chamada "humanização do parto" e mais acentuadamente com os atores e atrizes do "modelo holístico", atuantes em geral nos grandes centros urbanos. É possível então situar os discursos e representações das práticas de parturição apresentadas pelas mulheres quilombolas do Iguape com a conceituação da antropóloga DavisFloyd (1994, p. 7).

Um dos diferenciais da abordagem holística e humanizada é justamente supor, aceitar que a tecnologia e o modelo tecnocrático pode também produzir interferências negativas na unicidade "corpo-mente" e/ou "corpo-mente-espírito". O que compromete a cura enquanto um processo de cada corpo (de dentro para fora além de fora pra dentro), o processo fisiológico mais natural e consequentemente o desenvolvimento do trabalho de parto e parto. Diferente do modelo tecnocrático que é organizado de forma hierárquica a partir da consolidação da tecnologia como um conhecimento autoritativo, dos protocolos, burocracias, padronização dos cuidados e práticas visando uma suposta eficiência e produtividade em detrimento, muitas vezes, da individualidade de cada corpo (organismo, mente, espírito e ambiente).

Em se tratando do olhar sobre uso da tecnologia médica durante o ciclo gravídicopuerрeral as mulheres entrevistadas demonstraram um posicionamento equivalente ao dos profissionais, teóricos e militantes do chamado parto holístico. Ambos não recusam a tecnologia, mas tecem diversas críticas ao seu uso abusivo, muitas vezes sobreposto ao bem-estar do binômio mulher-bebê, respondendo a uma necessidade de resultados a curto prazo característico do etos das sociedades capitalistas modernas, visando um nível de eficiência e produtividade que diz respeito apenas a busca pela "melhora" e controle da natureza através do controle do corpo objetivando também contornar a possibilidade da morte. As mulheres do Iguape e defensores do modelo holístico e/ou humanizado parecem concordar ao afirmar, de maneiras distintas, que a tecnologia é utilizada de maneira abusiva devido ao valor simbólico que carrega, muito mais que pelo seu valor de cura. A tecnologia estaria a serviço da ilusão do controle e segurança absolutos ao mesmo passo que serve à ideologia calcada no progresso social, cultural e ambiental.

Assim, parece haver uma correlação entre as dinâmicas contemporâneas das comunidades do Vale do Iguape, em progressivo processo de interconexão com espaços 
urbanos, um sistema de saúde médico-hospitalar, a presença de novos agentes e mediadores externos e internos - de que a gradual diminuição do número de parteiras disponíveis e atuantes, observada ao longo da pesquisa de campo que realizei, é um indicador - num conjunto de fenômenos descontínuos transcorridos ao longo de décadas, e transformações nos próprios conceitos de corpo, saúde, cuidados, práticas e experiências de parto nessas comunidades, enredados em conflitos entre epistemes (o "tradicional" e o "científico"), sobre os quais incidem também significados relativos aos esforços de reinvenção e legitimação das suas identidades. Desse modo, cabe refletir sobre como um pretendido movimento de revalorização do parto dito "tradicional" e das figuras das parteiras populares, que se expressa nas várias iniciativas de adesão e difusão de modelos ditos "humanizados" ou "holísticos" e que se dispersa hoje por diferentes segmentos da comunidade médica, das instituições, de movimentos sociais, de mulheres em espaços urbanos e também por comunidades de composição social similar àquelas do Vale do Iguape, é interseccionado, no caso específico dessas comunidades, pela sua resignificação em face dos processos de afirmação, reivindicação e/ou reinvenção identitária, que estão na base da própria autodefinição dessas comunidades e das estratégias pelas quais procuram se relacionar com o Estado e com outros mediadores ou agentes exteriores à comunidade.

Falar sobre estratégias de antidisciplina e sobre assimilações do novo modelo obstétrico por parte das algumas parteiras locais e das comunidades em foco aqui, ou da atuação restrita de outra parte das parteiras que optaram por resistir ao processo de higienização, não significa dizer que todo o movimento realizado pelo Estado brasileiro e pela classe médica não tenha sido um movimento violento de perseguição e criminalização das parteiras, inscrito em um movimento muito maior de perseguição e criminalização das comunidades negras rurais do Brasil, principalmente das comunidades que foram se fortalecendo em um processo de autoidentificação enquanto remanescentes de quilombos. Higienizar, sanear, medicalizar, hospitalizar e mercantilizar a saúde e os partos significou nestas localidades um desalinhavar de parte dos sentidos que trançam o tecido social, cultural e político que as sustenta. Foram estratégias que podem ser compreendidas no âmbito das disputas de terra características do Brasil desde a colonização, das disputas por uma narrativa única, embranquecida e masculina, de país. Estratégias de controle social, dos corpos e das vidas mulheres, principalmente das mulheres negras e quilombolas.

Não é coincidência o fato de Lêu, moradora do Iguape, em conversa no dia 1 de dezembro de 2013, afirmar que as mulheres das comunidades quilombolas locais ao chegarem nos hospitais da região são maltratadas e violentadas pelos profissionais de saúde ao serem 
identificadas enquanto mulheres quilombolas, há uma nítida violência de gênero e étnica neste tipo de relato. Os territórios em disputa na região não são simples perímetros de terra, são "terras de preto" envolvidas em constantes disputas em torno de posse, usos, costumes e definições conceituais e jurídicas, e sentidos históricos. Os corpos negros e, mais ainda os das mulheres, estão também envolvidos em constantes disputas em torno de sua autonomia, saúde, trabalho, sexualidade, reprodução, histórias e direitos, tanto quanto os saberes e práticas aos quais estão corpos estavam, estão e estarão aos cuidados e reivindicando existências e horizontes. Finalmente, embora existam estas disputas visíveis em uma escola macro e micro, o que pude compreender junto àquelas mulheres e grupos nada mais é do que resistência histórica, reivindicação de existência na contemporaneidade a partir da autodeterminação, uma luta extensa e profunda por acesso a direitos diversos que não se resumem à terra, e, no que diz respeito a saúde, o desejo de uma intermedicalidade que dê conta de respeitar suas singularidades, trajetórias, história, organização social, cultural e política.

\section{REFERÊNCIAS}

ALVES, Paulo César. A teoria sociológica contemporânea: da superdeterminação pela teoria à historicidade. Sociedade e Estado, v. 25, n. 1, p. 15-31, 2010.

ALVES, Paulo César; RABELO, Miriam. Antropologia da saúde: traçando identidade e explorando fronteiras. Rio de Janeiro: Relumé Dumara, 1998.

ARRUTI, José Maurício A. Mocambo: História e antropologia do processo de formação quilombola. Bauru: EDUSC/ANPOCS, 2006.

ARRUTI, José Maurício A. Quilombos. In: SANSONE, L.; PINHO, O. Raça. Novas perspectivas antropológicas. Salvador: ABA/EdUFBA, 2008. p. 315-350.

BARTH, Fredrik. Introdução. In: BARTH, Fredrik. Los grupos étnicos y sus fronteras: La organización social de las diferencias culturales. FEC, México D.F., 1976. p. 9-49.

CARNEIRO DA CUNHA, Manuela. 'Cultura' e Cultura: conhecimentos tradicionais e direitos intelectuais. In: CARNEIRO DA CUNHA, Manuela. Cultura com aspas e outros ensaios. São Paulo: Casac Naify, 2009.

CARRANZA, Maria. De Cesáreas, Mulheres e Médicos. Dissertação de Mestrado, Brasília: Departamento de Pós-Graduação em Antropologia Social, Universidade de Brasília, 1994.

CLASTRES, Pierre. Crônica dos índios Guayaki. 0 que sabem os Aché caçadores nômades do Paraguai. São Paulo: Editora 34, 1995.

CONRAD, Peter. Medicalization and social control. Annual Review of Sociology, n. 18, p. 209-232, 1992. 
DAVIS-FLOYD, Robbie E. The technocratic body: American childbirth as a cultural expression. Social Science and Medicine, v. 38 ก. 1, p. 1125-1140, 1994.

DE ALMEIDA SILVA, Tânia Maria; FERREIRA, Luiz Otávio. A higienização das parteiras curiosas: o Serviço Especial de Saúde Pública e a assistência materno infantil (1940-1960). História, Ciências, Saúde Manguinhos, v. 18, p. 95-112, 2011.

DINIZ, Carmen Simone Grilo. Humanização da assistência ao parto no Brasil: os muitos sentidos de um movimento. Ciência e saúde coletiva, v. 10, n. 3, p. 627-637, 2005.

EHRENREICH, Barbara; ENGLISH, Deirdre. Brujas, Parteras y Enfermeras: Uma historia de sanadoras femininas. Printed by the Faculty Press, Broonkly, NY. Edición Española, Editorial La Sal, Barcelona, 1981.

FLEISCHER, Soraya Resende. Parteiras, buchudas e aperreios. Uma etnografia do atendimento obstétrico não oficial em Melgaço, Pará. Belém: Paka-Tatu, EdUnisc, 2011.

FOUCAULT, Michel. A arqueologia do saber. Rio de Janeiro: Forense Universitária, 1987.

LE BRETON, David. Antropologia do corpo e modernidade. Petrópolis: Vozes, 2011.

LEITE, Ilka Boaventura. Terras e territórios de negros no Brasil. Textos e Debates, v. 1. n. 2, 1991.

LIMA, Nísia Trindade; HOCHMAN, Gilberto. Condenado pela raça, absolvido pela medicina: 0 Brasil descoberto pelo movimento sanitarista da Primeira República. Raça, ciência e sociedade, v. 1, p. 23-40, 1996.

MARTIN, Emily. A mulher no corpo. Uma análise cultural da reprodução. Rio de Janeiro, Editora Garamond, 2006.

LÉVI-STRAUSS, Claude. 0 pensamento selvagem. São Paulo, CEN, 1976 [1962].

MAUSS, M. Sociologia e antropologia. São Paulo, Cosac e Naify, 2005.

MCCALLUM, Cecília. 0 saber antropológico e a totalidade nos fatos sociais. Comunicação apresentada no seminário temático "A antropologia e seus métodos: o arquivo, o campo, os problemas", XXV Encontro Anual da ANPOCS, Caxambu. Mimeo (citado com permissão da autora em e-mail de 29 de novembro de 2006), 2001.

ROHDEN, Fabíola. Uma ciência da diferença: sexo e gênero na medicina da mulher. Rio de Janeiro, Editora Fiocruz, 2001.

SAHLINS, Marshall. 0 pessimismo sentimental e a experiência etnográfica: porque a cultura não é um objeto em extinção (parte I e parte II). Mana, v. 3, n. 1, p. 41 73, 1997.

SPIVAK, Gayatri S. A critique of postcolonial reason. Toward a history of the vanishing present. Cambridge, MA: Harvard University Press, 1999. 
STRATHERN, Marilyn. Necessidade de pais, necessidade de mães. Revista Estudos Feministas, v. 3, n. 2, p. 303-330, 1995.

TORLONI, Maria Regina; MORON, Antonio Fernandes; CAMANO, Luiz. Placenta Prévia: Fatores de risco para 0 Acretismo. Rev. Bras. Ginecol. Obstet. [online], v. 23, n. 7, p.417-422, 2001.

TORNQUIST, Carmen Susana. Armadilhas da nova era: natureza e maternidade no ideário da humanização do parto. Revista Estudos Feministas, v. 2, n. 10, p. 483-492, 2002.

VIEIRA, E. M. A medicalização do corpo feminino. Rio de Janeiro: Fiocruz, 2003.

Recebido em 13 de setembro de 2018. Aprovado em 07 de julho de 2019. 